\title{
Pathogen-Specific Impacts of the 2011-2012 La Niña-Associated Floods on Enteric Infections in the MAL-ED Peru Cohort: A Comparative Interrupted Time Series Analysis
}

\author{
Josh Colston ${ }^{1}$, Maribel Paredes Olortegui ${ }^{2}$, Benjamin Zaitchik ${ }^{3}$, Pablo Peñataro Yori ${ }^{4}$, \\ Gagandeep Kang ${ }^{5}$, Tahmeed Ahmed ${ }^{6}$, Pascal Bessong ${ }^{7}{ }^{\mathbb{D}}$, Esto Mduma ${ }^{8}$, Zulfiqar Bhutta ${ }^{9}$, \\ Prakash Sunder Shrestha ${ }^{10}$, Aldo Lima ${ }^{11}$ and Margaret Kosek ${ }^{4, *}$ \\ 1 Division of Infectious Diseases and International Health, University of Virginia School of Medicine, \\ Charlottesville, VA 22903, USA; josh.colston@virginia.edu \\ 2 Asociación Benéfica Prisma, Iquitos 16006, Peru; mparedeso@prisma.org.pe \\ 3 Department of Earth and Planetary Sciences, Johns Hopkins Krieger School of Arts and Sciences, Baltimore, \\ MD 21218, USA; zaitchik@jhu.edu \\ 4 Division of Infectious Diseases and International Health, University of Virginia, Charlottesville, VA 22903, \\ USA; pyori@virginia.edu \\ $5 \quad$ Christian Medical College, Vellore 632004, India; gkang@cmcvellore.ac.in \\ 6 Nutrition \& Clinical Services Division, International Centre for Diarrhoeal Disease Research, \\ Bangladesh (icddr,b), Dhaka 1213, Bangladesh; tahmeed@icddrb.org \\ 7 University of Venda, Thohoyandou 0950, South Africa; Pascal.Bessong@univen.ac.za \\ 8 Haydom Global Health Institute, Haydom P.O. Box 9000, Tanzania; estomduma@gmail.com \\ 9 Department of Pediatrics and Child Health, Aga Khan University, Karachi 74800, Pakistan; \\ zulfiqar.bhutta@aku.edu \\ 10 Department of Child Health, Institute of Medicine of Tribhuvan University, Kirtipur 44618, Nepal; \\ prakashsunder@hotmail.com \\ 11 Federal University of Ceará, Fortaleza 60020-181, Brazil; alima@ufc.br \\ * Correspondence: mkosek@virginia.edu
}

Received: 4 December 2019; Accepted: 9 January 2020; Published: 12 January 2020

\begin{abstract}
Extreme floods pose multiple direct and indirect health risks. These risks include contamination of water, food, and the environment, often causing outbreaks of diarrheal disease. Evidence regarding the effects of flooding on individual diarrhea-causing pathogens is limited, but is urgently needed in order to plan and implement interventions and prioritize resources before climate-related disasters strike. This study applied a causal inference approach to data from a multisite study that deployed broadly inclusive diagnostics for numerous high-burden common enteropathogens. Relative risks (RRs) of infection with each pathogen during a flooding disaster that occurred at one of the sites-Loreto, Peru-were calculated from generalized linear models using a comparative interrupted time series framework with the other sites as a comparison group and adjusting for background seasonality. During the early period of the flood, increased risk of heat-stable enterotoxigenic E. coli (ST-ETEC) was identified $(\mathrm{RR}=1.73[1.10,2.71])$ along with a decreased risk of enteric adenovirus $(R R=0.36[0.23,0.58])$. During the later period of the flood, sharp increases in the risk of rotavirus $(R R=5.30[2.70,10.40])$ and sapovirus $(R R=2.47[1.79,3.41])$ were observed, in addition to increases in transmission of Shigella spp. $(\mathrm{RR}=2.86[1.81,4.52])$ and Campylobacter spp. $(\mathrm{RR}=1.41(1.01,1.07)$. Genotype-specific exploratory analysis reveals that the rise in rotavirus transmission during the flood was likely due to the introduction of a locally atypical, non-vaccine (G2P[4]) strain of the virus. Policy-makers should target interventions towards these pathogens-including vaccines as they become available-in settings where vulnerability to flooding is high as part of disaster preparedness strategies, while investments in radical, transformative, community-wide, and locally-tailored water and sanitation interventions are also needed.
\end{abstract}


Keywords: climate change; diarrheal disease; infectious disease; ENSO; La Niña; flooding; natural disasters; enteric viruses; enteric bacteria; rotavirus

\section{Introduction}

Climate change is increasingly understood to represent an impending global public health threat, since numerous health outcomes are sensitive to meteorological patterns [1,2]. In addition to rising surface temperatures, variability in precipitation and evapotranspiration is set to increase in the coming decades, exaggerating the pattern of high rainfall at the equator and polar fronts and low rainfall across the subtropical heights [3]. The impacts of changing rainfall patterns on health will likely not be linear but felt most pronouncedly at the extremes, with both heavy precipitation events and more frequent droughts making water sources and food systems more precarious and disease and injury more likely [4-6]. Floods, already the most common type of national disaster, are likely to increase in frequency and severity in many regions as climate change brings about sea level rises and shifts in rainfall patterns [7-9]. There is particular reason for concern in the Amazon, where La Niña conditions are associated with major floods, including the record floods of 2012 [10,11], and where recent intensification of flood events may be the result of a climate change induced trend towards La Niña, such as sea surface temperature patterns [12].

The health impacts of floods are manifold and include injury and drowning, toxic exposure, and increased transmission of vector- and waterborne diseases [9], but enteric disease outbreaks are one of the most widely recognized [6]. Following heavy precipitation events, floodwater and surface runoff may overwhelm drainage and wastewater systems, causing the dispersal of enteric viruses, bacteria and protozoa through the environment and the contamination of surface and groundwater supplies as well as crops $[6,7,13-15]$. Those most vulnerable to these hazards will be populations in low-resource countries, as rapid, unplanned urbanization leads increasing numbers of people to settle in neighborhoods with inadequate water, sanitation, and drainage infrastructure [9].

While diarrheal disease outbreaks in the wake of floods are regularly documented $[7,16,17]$, and some context-specific studies have attributed these to individual pathogens $[9,18,19]$, the precise causal pathways underlying these associations are not well understood. They are likely to be complex and time-dependent [6]. Different pathogen species and taxa possess their own distinct transmission dynamics and dominate or recede in importance as time elapses following the onset of a flood $[7,20]$, highlighting the need to characterize impacts by etiological agent [6]. Furthermore, the relative roles of direct exposure to fecal contamination due to floodwaters compared to secondary effects of crowding and increased contact rates as a result of population displacement are not well delineated [21].

One approach to estimating the impact of flooding events on human health is to treat it as a 'natural experiment' by identifying disease surveillance data that spans the duration of the event as well as a sufficient pre- and post-flood comparison period providing a time series to which causal inference methods can be applied. Several studies using health information system data from China within case-crossover or interrupted time series (ITS) analyses have quantified significant increases in diarrheal disease and bacillary dysentery following floods in Anhui and Hunan provinces, respectively [22-24]. However, new diagnostic methods applied in multi-site, population-based studies now make it possible to characterize pathogen-specific trends in both diarrheal and asymptomatic enteric infections [25-27]. Using information from one such study, which happened to coincide with a La Niña-related flooding disaster, the objective of the analysis presented here was to use a comparative ITS analysis to derive causal inferences about the species-specific impacts of this event on enteric pathogen infections. 


\section{Materials and Methods}

\subsection{Study Setting}

As part of the Etiology, Risk Factors and Interactions of Enteric Infections and Malnutrition and the Consequences for Child Health and Development (MAL-ED) project, data was collected from birth cohorts recruited from eight communities, each in a different low- or middle-income country [28]. Subjects were enrolled and monitored continuously over their first 2 years of life from November 2009 to March 2014. Written informed consent was obtained from the caregiver of all participating children.

One of the MAL-ED study sites is located in Santa Clara de Nanay, a peri-urban community located $15 \mathrm{~km}$ from the city of Iquitos in the Loreto province of Peru, in a low-lying equatorial rainforest area situated at the confluence of several Amazon tributaries [29]. Since waterways are the main transport infrastructure in this region, the large majority of the population is located on or in close proximity to the banks of rivers, making them particularly vulnerable to flooding. In late 2011 and early 2012, around midway through MAL-ED follow-up and under the strong influence of the 2010-12 La Niña event $[10,11]$, the region was hit by widespread riverine floods after heavy rains over the preceding months caused the Ucayali, Marañón, and Nanay rivers to burst their banks [30,31]. In Santa Clara, torrential downpours began on November 15, 2011; and by December, around half of all households in the community had been displaced by flooding (Figure 1) and forced to evacuate their homes until March or April of 2012. The regional government of Loreto established temporary shelters for the displaced throughout the affected areas and, at the end of March of that year, declared the situation a state of emergency affecting over 191,000 inhabitants [31]. Heavy rains and the rise in river levels continued, on April 11 the weather station at the nearby airport recorded rainfall of $20 \mathrm{~cm}$ and by one week later, the Nanay River had risen to a level of 118.24 meters above sea level, its highest since 1986 (Figure 2) [32,33]. By the end of the disaster, an estimated 50,000 people had been made homeless [34].

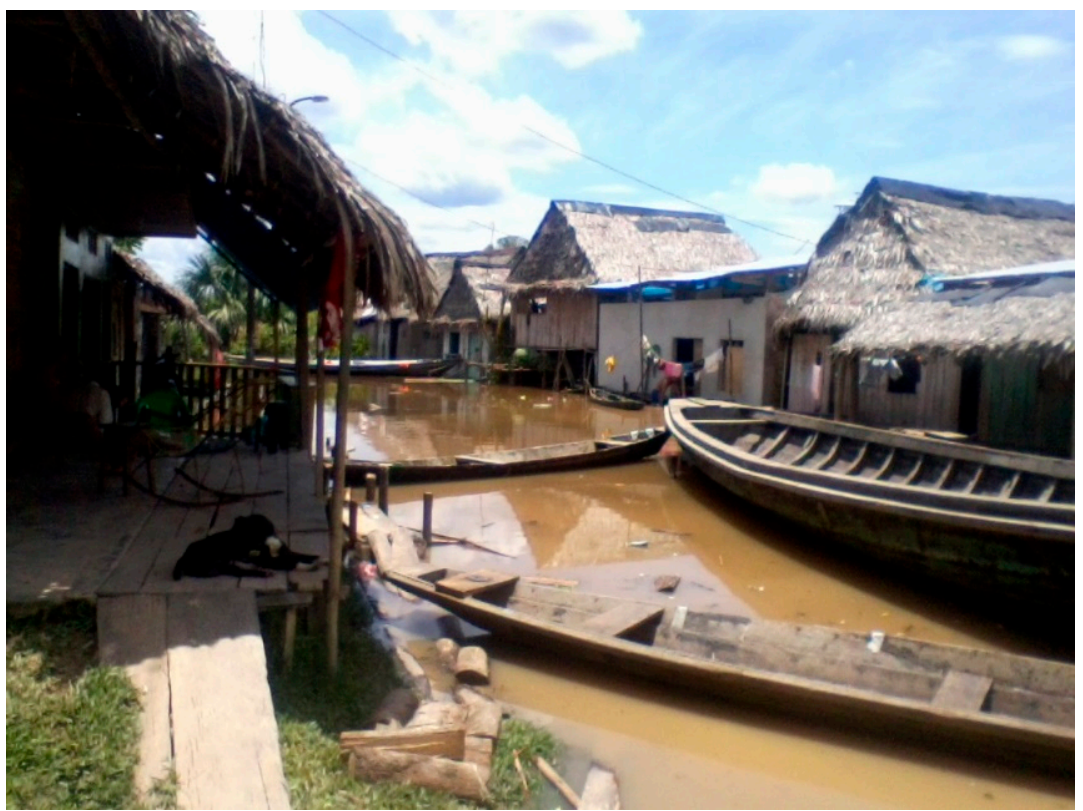

Figure 1. A flooded street in Santa Clara de Nanay, April 2, 2012 (courtesy of Asociación Benéfica Prisma). 


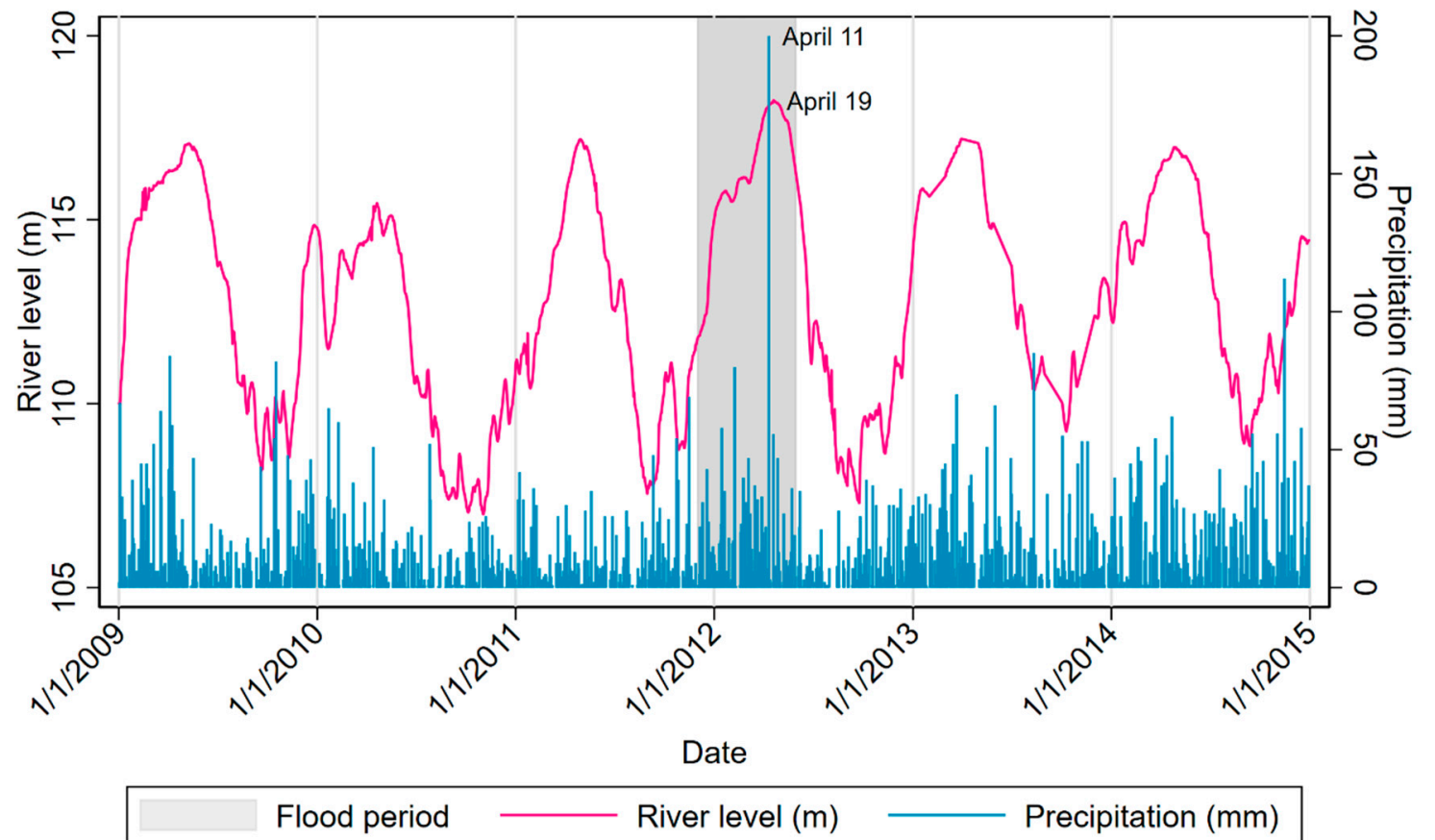

Figure 2. Daily precipitation volume measured at Coronel FAP Francisco Secada Vignetta International Airport 2009-2014 and levels of the Nanay River obtained from Sede Loreto at their intake station on the Nanay River [32,33].

\subsection{Outcome Variables}

Stool samples were collected from the subjects according to a predefined schedule at monthly intervals following enrollment in MAL-ED and upon reporting of a diarrheal episode by the child's caregiver. For samples from subjects who completed follow-up, enteropathogen-specific infection status was ascertained using probe-based quantitative PCR (qPCR) assays on custom-developed TaqMan Array Cards (Thermo Fisher) [35]. For other samples, enzyme-linked immunosorbent assay (ELISA) was used to test for adenovirus, astrovirus, Campylobacter, Cryptosporidum, Giardia, and rotavirus, other bacteria species were assessed by culture with E. coli pathotypes confirmed by polymerase chain reaction (PCR), and norovirus was detected using reverse-transcription PCR [36]. The pathogen species included in this analysis were: adenovirus, astrovirus, norovirus, rotavirus, sapovirus, Campylobacter, enteroaggregative E. coli (EAEC), enteropathogenic E. coli (EPEC, typical and atypical), heat-labile enterotoxigenic E. coli (LT-ETEC), and heat-stable ETEC (ST-ETEC), Salmonella, Shigella/enteroinvasive E. coli (EIEC) (qPCR uses the same gene target for these two related pathogens), Cryptosporidium, and Giardia. To ensure that a single infection episode was not counted multiple times, Campylobacterand norovirus-positive samples were excluded if they were collected within 30 days of a previous sample that was positive for the same pathogen strain without being separated by an intermediate negative sample. For all other pathogens, a 14-day period was used, except for the two protozoa, for which samples that were positive for the same species (C. parvum or C. hominis) or assemblage (G. duodenalis A or B) as a prior sample from the same subject were excluded unless separated by three negative samples.

\subsection{Exposure Variables}

The main exposure of interest-the 'intervention' in this ITS analysis-was whether the stool samples were collected during the approximate period of the flood. Two periods were considered and modeled separately using the same methods: the early flood period from December 1, 2011 to February 29, 2012, during which time the study community was flooded and many households were displaced; and the late flood period from March 1 to May 31, 2012, during which time evacuees returned to the 
community, but rains and flooding continued throughout the wider Loreto region. Sample-level binary dummy variables were therefore constructed that were coded as 1 if the sample was collected during the relevant flood period or 0 otherwise (the pre-/post-flood) [37]. The study therefore had a 'BAB' design (an inversion of the 'ABA' design as defined by Biglan and colleagues) since it includes the time before the intervention was introduced and the time after it was withdrawn [38]. Data from all eight sites were included in the analysis with the seven other sites used as a comparison group of concurrent reference populations to provide an external comparator to discount concurrent pandemic changes in incidence as alternative hypothesis to the observed differences during the risk period under evaluation in Loreto. A second binary dummy variable was therefore introduced corresponding to whether the subject was in the 'treatment' (Peru) or 'control' cohorts (the other seven sites) [37]. To adjust for background cyclical trends due to disease seasonality, terms for the interactions between annual and biannual Fourier-series sine and cosine functions terms and indicator variables for the eight sites were included in the model with the terms for the main effect omitted, thus allowing for up to two annual peaks and differences in their site-specific timing and magnitude [39,40]. In addition, the non-linear effect of age was modeled using linear, quadratic and cubic terms for the child's age in continuous months. Study site, stool specimen type (diarrheal or surveillance) and diagnostic method (qPCR or conventional methods) were also adjusted for using indicator variables.

\subsection{Statistical Methods}

Modified Poisson regression models were fitted to each of the binary pathogen outcomes in turn using generalized linear models with cluster-robust variance estimation to calculate adjusted risk ratios (RRs) for infection [41]. The models assumed the following form (adapted from Linden and colleagues and Colston and colleagues [37,39]):

$$
\operatorname{logit} P(Y i t=1)=\beta_{0}+\beta_{1} T+\beta_{2} I_{t}+\beta_{3} T_{t}+\beta_{4} Z+\beta_{5} Z T+\beta_{6} Z I_{t}+\beta_{7} Z I_{t} T+\cdots+\beta_{n} X_{n}
$$

where $\mathrm{P}($ Yit $=1)$ is the probability of a stool from subject $i$ being positive for pathogen $Y$ on date $t$; $T$ is the time in continuous months since the start of follow-up; $I_{t}$ is the dummy variable representing whether the intervention was in place at time $t$ (i.e., whether date $t$ took place between March and May of 2012); $Z$ is the dummy variable denoting treatment or control cohort assignment; and $X_{n}$ are the covariates used for adjustment but not for estimating the main effect of the flood. In this equation, $\beta_{6}$ estimates the difference in the magnitude of the outcome variable immediately following the introduction of the intervention and can be interpreted as the difference in the RR of detection of pathogen $Y$ at the start of the flood period compared with immediately before. $\beta_{7}$ represents the change in the outcome per unit of time while the intervention is in place - the trajectory of the relative risk during the flood. The estimates of $\beta_{6}$ and $\beta_{7}$ from each model were visualized in forest plots, and for pathogens for which these estimates were statistically significant at the $\alpha=0.05$ level, the trajectories in the probabilities of infection (calculated from the RRs estimated by the models) over the course of follow-up were plotted. As a secondary, exploratory analysis, detections of specific rotavirus genotypes were plotted in needle plots to visually assess differences in their timing relative to the flood periods. Analyses were carried out in Stata 15.1 (StataCorp, College Station, Texas, USA) [42].

\section{Results}

Table 1 shows the distribution of positive detections of the different species of enteropathogens in stool samples from the MAL-ED Peru site during early and late flood periods and the pre-/post-flood period, as well as their overall distribution in samples from the other seven sites. In all periods and in both treatment and control group, the most prevalent pathogen was EAEC followed by Campylobacter. Norovirus, sapovirus, and Giardia were also highly prevalent. The needle plots in Figure S1 in the supporting information show the daily distribution of pathogen-positive stool samples recorded at the Peru site by species. 
Table 1. Number and percentages (\%) of stool samples that were positive for different species of enteropathogens in the MAL-ED Peru site during three periods relative to the flood and in the other seven study sites (control group) overall.

\begin{tabular}{ccccc}
\hline Pathogen & Early Flood & Late Flood & Pre-/Post-Flood & Control Group \\
\hline Adenovirus 40/41 & $77(9.0)$ & $129(15.4)$ & $1171(18.3)$ & $4545(10.9)$ \\
\hline Astrovirus & $114(13.5)$ & $121(14.5)$ & $859(13.4)$ & $3800(9.1)$ \\
\hline Norovirus & $96(13.6)$ & $135(18.5)$ & $1189(21.6)$ & $6002(15.8)$ \\
\hline Rotavirus & $25(2.9)$ & $85(10.2)$ & $173(2.6)$ & $2027(4.8)$ \\
\hline Sapovirus & $119(20.5)$ & $122(20.3)$ & $689(15.4)$ & $4693(13.3)$ \\
\hline Campylobacter spp. & $202(24.4)$ & $194(23.7)$ & $1,386(22.3)$ & $10,248(25.6)$ \\
\hline EAEC & $359(47.1)$ & $379(48.8)$ & $2,585(43.3)$ & $17,414(42.6)$ \\
\hline Atypical EPEC & $176(21.3)$ & $162(20.0)$ & $1,212(19.2)$ & $8,593(20.5)$ \\
\hline Typical EPEC & $70(8.4)$ & $97(11.9)$ & $622(9.7)$ & $4344(10.4)$ \\
\hline LT-ETEC & $113(13.5)$ & $132(16.2)$ & $918(14.4)$ & $4766(11.4)$ \\
\hline ST-ETEC & $88(10.6)$ & $80(9.7)$ & $584(9.1)$ & $5,397(12.9)$ \\
\hline Salmonella spp. & $7(0.8)$ & $10(1.1)$ & $50(0.7)$ & $264(0.6)$ \\
\hline Shigella spp./EIEC & $86(9.5)$ & $125(14.4)$ & $606(9.0)$ & $4126(9.8)$ \\
\hline Cryptosporidium spp. & $78(9.4)$ & $44(5.3)$ & $507(8.1)$ & $2183(5.3)$ \\
\hline Giardia spp. & $125(17.4)$ & $156(22.4)$ & $1117(20.8)$ & $5998(16.7)$ \\
\hline
\end{tabular}

The forest plots in Figure 3 visualize the risk ratios and their confidence intervals and significance levels estimated by the two models for the detection of each enteric pathogen species in the two flood periods relative to the pre-/post-flood period and to the control sites adjusted for confounders. During the early period of the flood, ST-ETEC was the only pathogen for which an increased risk was observed-a slightly statistically significant $73 \%$ increase $(R R=1.73[1.10,2.71])$ relative to the non-flood period and control group, which decreased by $27 \%$ per month following the start of that period $(\mathrm{RR}=0.73[0.57,0.92])$. Adenovirus exhibited a highly and sapovirus a moderately statistically significant decrease in risk during the early flood period (RRs respectively 0.36 [0.23, 0.58] and $0.52[0.31,0.89])$. During the later period of the flood, the largest RR of any of the pathogens was observed for rotavirus, an increase in risk of over $500 \%$ relative to the pre-/post-flood period and control group $(R R=5.30[2.70,10.40])$. Risk of sapovirus also increased substantially and highly statistically significantly by almost $250 \%(R R=2.47[1.79,3.41])$, while a highly statistically significant decrease in astrovirus risk was observed $(R R=0.44[0.29,0.66])$. Among the enteric bacteria, the largest effect size was seen for Shigella spp., risk of which almost tripled in the late flood period compared to the non-flooded period and control group ( $R R=2.86[1.81,4.52])$, while a slightly statistically significant increase in the risk of Campylobacter spp. was also observed ( $R R=1.41[1.01,1.97])$. No associations with either of the two protozoa were significant at the $\alpha=0.05$ level, although a decrease in risk of Giardia spp. during the early flood period was borderline significant. Pathogens with statistically significant differences in levels in the intervention periods tended to have differences in trajectory of corresponding significance and magnitude in the other direction, indicating that changes in transmission reverted to background levels relatively promptly (the notable exception being rotavirus).

Figure 5 shows the trajectories predicted by the models over the course of follow-up after the RRs were converted to probabilities for the seven pathogens for which statistically significant effects were identified. For adenovirus the models predicted biannual seasonality in transmission at the Peru site with a primary peak in November and a secondary, mid-year peak. The flood started during the primary peak and an immediate decrease in the probability of adenovirus was detected, which persisted into the late flood period, but had returned to pre-flood levels by the end of May 2012. Astrovirus 
exhibited a single annual peak occurring early in the year. This pattern did not appear to be disrupted in the early flood period, but in the later period, the probability of infection decreased substantially, before returning to pre-flood levels. Compared with other viruses, rotavirus transmission at this site was low (Peru introduced the Rotarix vaccine in 2008 [29]), with a single midyear peak. During the year of the flood, probability of infection rose early and was sustained through the late flood period at a level higher than the normal seasonal peak. Sapovirus did not demonstrate marked seasonality, but probability of infection rose to several times the normal level over the course of the early flood period and decreased to a lower level than normal in the late period. The trend for Campylobacter showed low-amplitude, biannual seasonality with upticks at the very start of both the early and late flood periods. ST-ETEC had a single annual peak in the first quarter of the year and also showed evidence of an off-peak uptick at the start of the early flood period, with trends during the late flood returning to approximately the pre-/post-flood pattern. Transmission of Shigella spp./EIEC showed little seasonal variation, rose over the early flood period and had not returned to normal levels by the end of the late flood period.

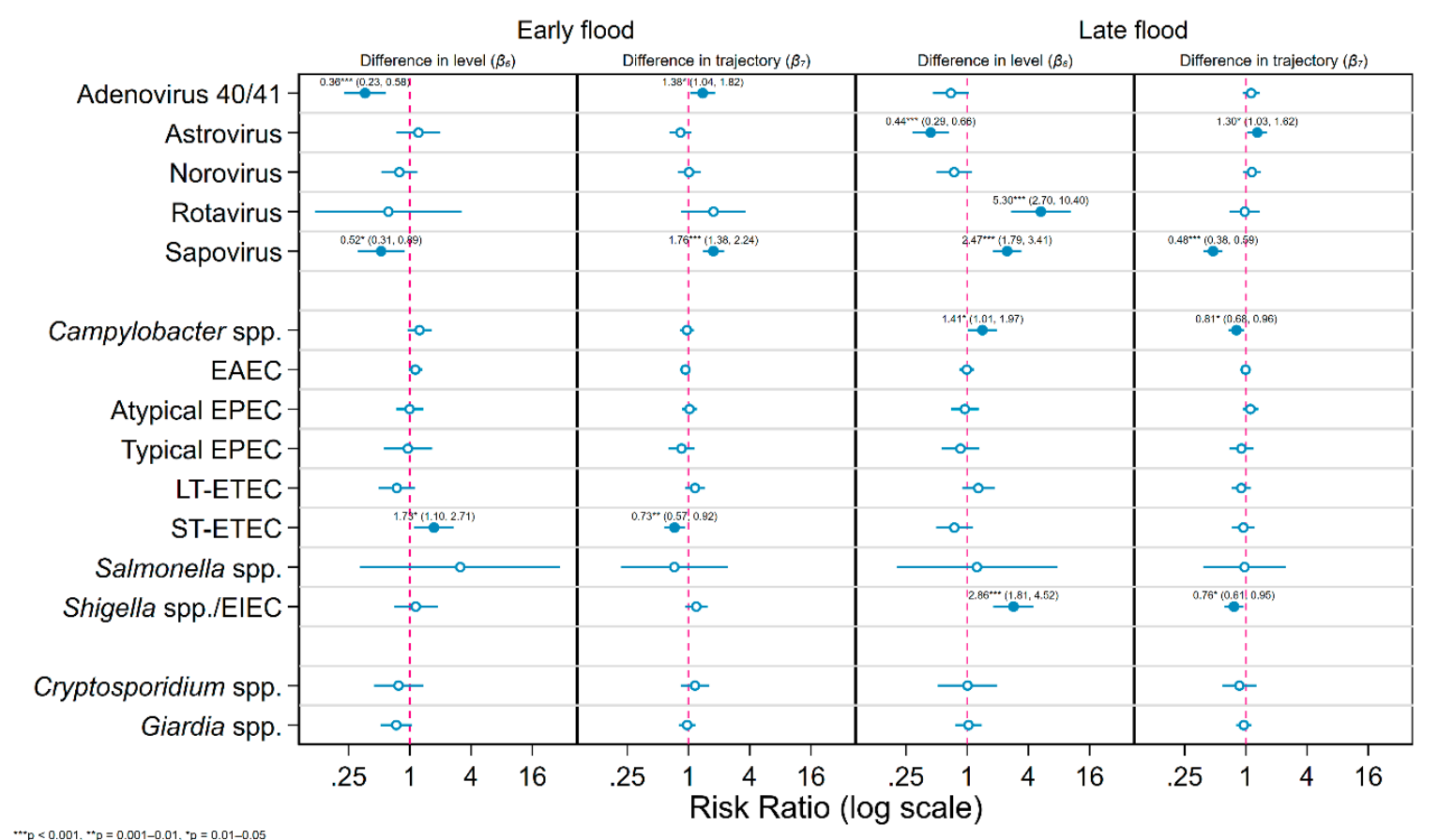

Figure 3. Risk ratios for detection of specific enteric pathogen species in stool samples collected from infants aged 0-2 years during each of the two flood periods relative to the pre-/post-flood period and to the control sites estimated for generalized linear models that adjusted for seasonality, site, age, sample type, and diagnostic method.

The needle plots in Figure 6 show the daily distribution of rotavirus-positive stool samples recorded at the Peru site by genotype. While G1 and P[8] types occurred evenly and G8, G9, and G12 sporadically throughout the follow-up period, the majority of G2 and P4 rotavirus episodes were recorded in a cluster starting at the end of the early flood period and continuing beyond the end of the late flood period. A similar, but less pronounced cluster of G3 and P6 rotavirus episodes began towards the end of the late flood period. 


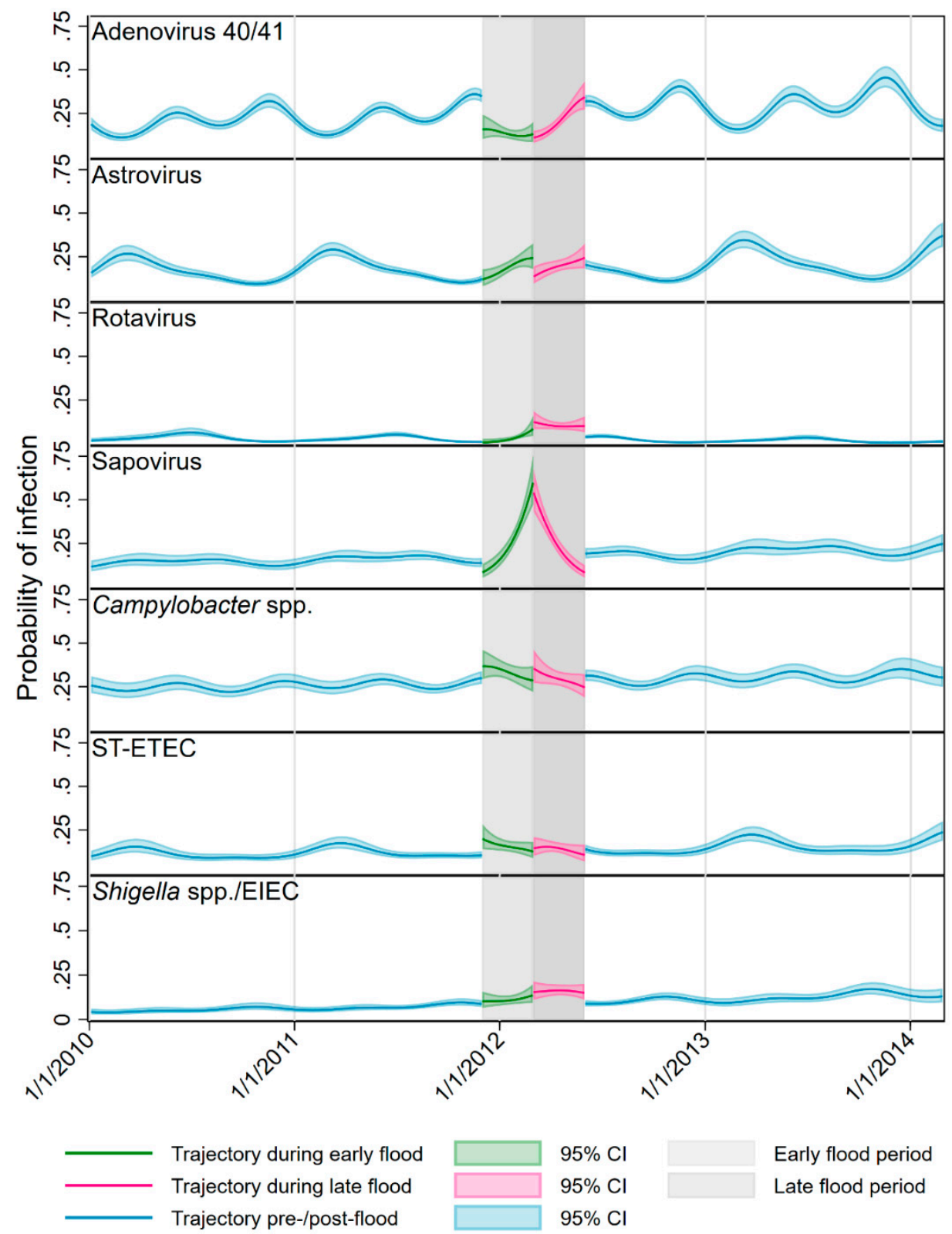

Figure 4. Transmission trajectories predicted by the models with (confidence intervals-CIs) for the seven pathogens that exhibited statistically significant effects (probabilities calculated from relative risk estimates). 


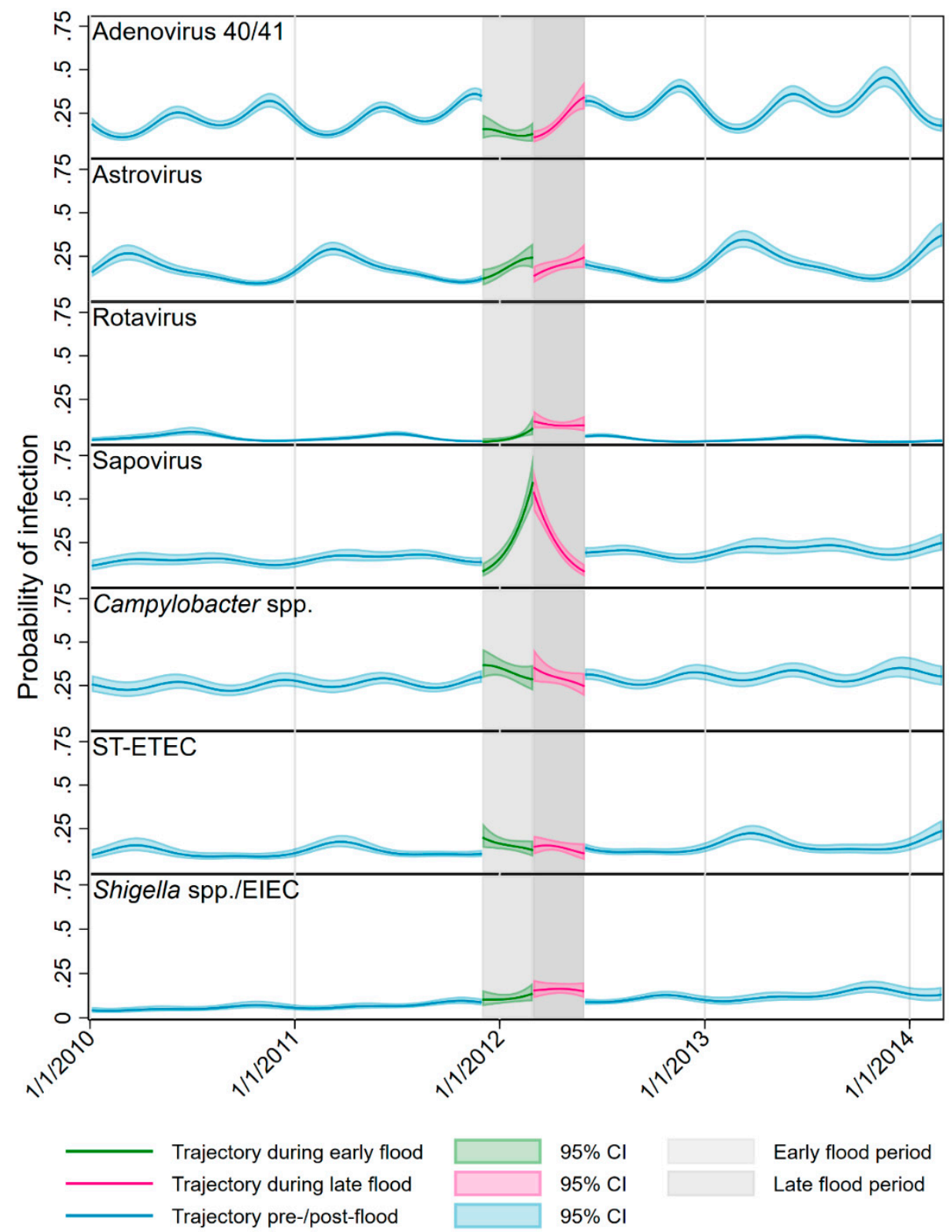

Figure 5. Transmission trajectories predicted by the models with (confidence intervals-CIs) for the seven pathogens that exhibited statistically significant effects (probabilities calculated from relative risk estimates). 


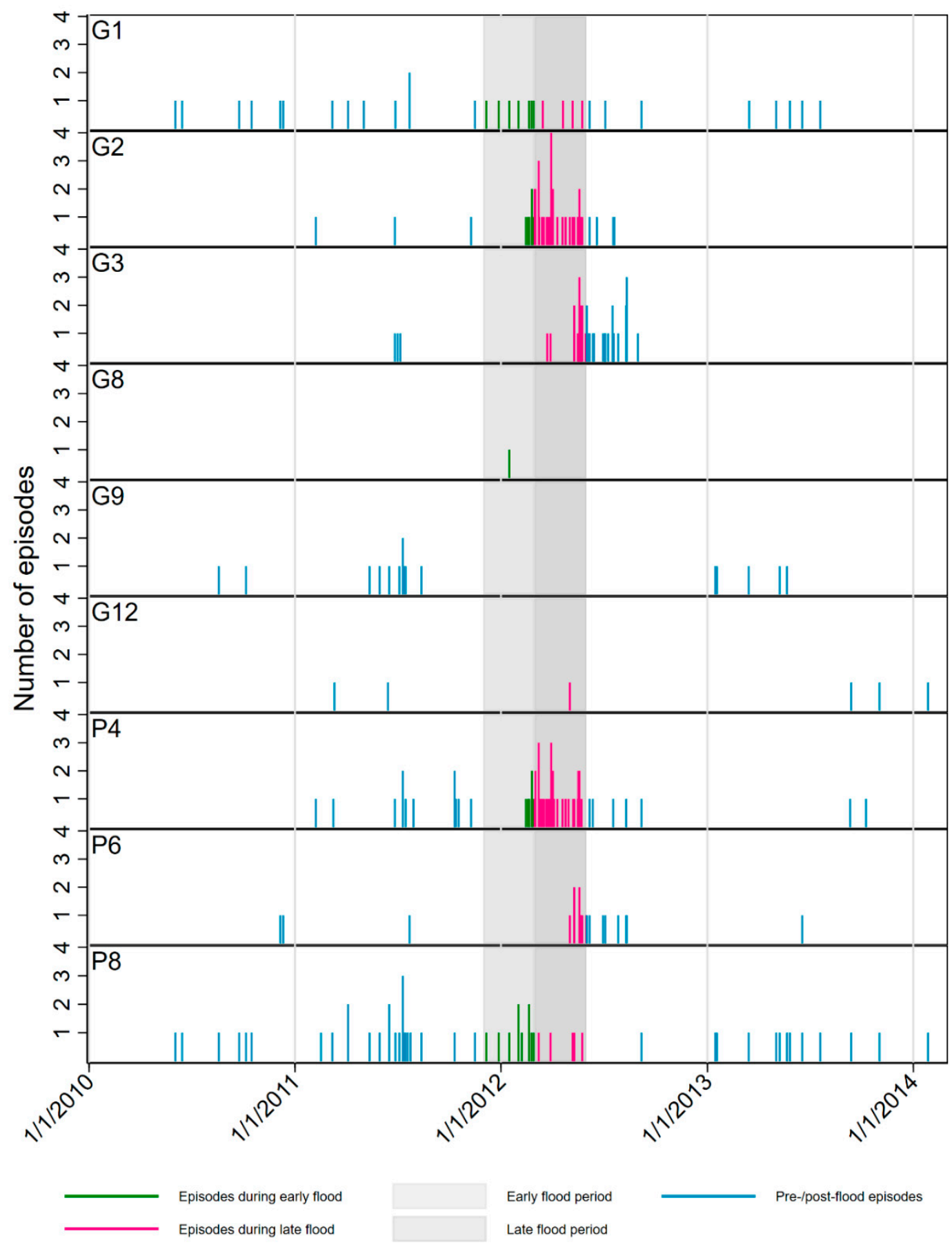

Figure 6. Needle plots of the daily distribution of rotavirus-positive stool samples recorded at the MAL-ED Peru site by genotype.

\section{Discussion}

In order for health systems to adapt to mitigate the impacts of climate change, evidence is needed of the impacts of extreme weather events on specific outcomes of public health importance. The El Niño-Southern Oscillation (ENSO) phenomenon is a cause of both flooding and droughts across multiple continents and has been shown to be associated with increases in childhood diarrhea in Peru, the United States and elsewhere [43-45]. Climate change may increase the frequency of ENSO events as well as the global land area that is subject to its precipitation impacts [46,47]. Evidence regarding the effects of flooding on individual diarrhea-causing pathogens is limited, but is urgently needed in 
order to plan and implement interventions and prioritize resources before climate-related disasters strike. This study applied a causal inference approach to data collected from infants enrolled in a multisite study that deployed broadly inclusive diagnostics for common enteropathogens that are among those most closely linked to cases of moderate and severe diarrhea [26,48]. In doing so, statistically significant increases in the prevalence of several important pathogens during the course of the flood were identified-including rotavirus, sapovirus, ST-ETEC, and Campylobacter spp. and Shigella spp.-strongly suggesting that the transmission of these pathogens are most sensitive to flooding in this context. Numerous other pathogens did not show statistically significant effects, indicating that they may not be responsive to floods, findings which, if replicated elsewhere, may mean that they can be deprioritized in disaster preparedness policies.

Risk of ST-ETEC infection in the cohort was elevated during the first three months of the flood period, but not during the later phase. ETEC is easily transmitted in contaminated water and frequently detected in surface water in riverine settings, environments where it is adapted to survive by upregulating certain genes involved in membrane stability and by forming biofilms $[49,50]$. Evidence from successive floods in Bangladesh strongly implicate these events as major drivers of ETEC diarrhea, though the dominance of the ST-relative to the LT-producing form appeared to vary $[17,21,49]$. Elevated risk of infection with Campylobacter spp. and Shigella spp./EIEC—both bacterial enteropathogens with low infectious doses-were identified in the late flood period. Campylobacter is a zoonotic bacterium for which poultry is a primary reservoir and can survive in surface waters and aquatic environments [51,52]. Observed increases in the incidence of campylobacteriosis following extreme precipitation events are thought to be due, at least in part, to the contamination of water sources by runoff from concentrated animal feeding operations (CAFO) [53]. It is possible that the results from Santa Clara represent a smaller-scale version of this process, occurring in a community with high rates of household chicken ownership.

While no significant difference in rotavirus prevalence was observed during the first three months of the flood, the late flood period saw a five-fold increase in rotavirus infection risk, the largest relative effect identified by this analysis. While the primary routes of rotavirus transmission involve direct person-to-person transmission or contact with contaminated surfaces and fomites, the importance of waterborne transmission is gaining salience [54]. Flooding in the Solomon Islands in 2014 caused a nationwide outbreak of rotavirus diarrhea [55], while recent evidence from Bangladesh have linked both particular precipitation events—notably the 2007 flood [17] — and rainy days in general to upticks in rotavirus [56]. Previous analyses of data from the South Asian MAL-ED sites have identified secondary seasonal peaks in rotavirus coinciding with the annual monsoon season $[39,57]$ and recent findings of a protective effect of drinking water from tube wells are consistent with these results, since these water supply systems draw upon deeper groundwater reserves that are better protected from flood-related contamination than sources nearer to the surface [58]. Mechanistic simulation modeling has demonstrated that dissemination of rotavirus between communities connected by waterways can be an important indirect route of transmission in tropical environments that is modified by flow velocity [54]. It is possible that differences in the flow rate of the floodwaters may explain why an effect was observed in the late but not the early flood period.

The exploratory analysis of the epidemiology of the specific rotavirus genotypes at the Peru MAL-ED site suggest that a small outbreak of G2P[4] type virus occurred starting in late February 2012, with a smaller outbreak of G3P[6] type starting towards the end of the late flood period. Although sporadic identifications did occur outside of the flood period, these are generally atypical genotypes in this setting, where G1 and P[8] - the combination that are the target of the Rotarix vaccine used at this site-are by far the dominant circulating genotypes. Indeed, a later cohort study recruited from the same community in 2018 (a year in which no substantial flooding occurred), carried out during the local annual rotavirus peak found only G1 and P[8] genotypes in circulation (unpublished results). A possible explanation for these findings is that as a result of the flood, locally atypical, non-vaccine rotavirus strains were introduced to the community-either carried along the 
waterways by floodwater from upstream communities, or else brought by returning evacuees acting as hosts-which then briefly took hold. While estimates of Rotarix efficacy against G2P[4] vary, they are generally lower than for the target genotype (41\% compared to $92 \%$ in one study [59] 85\% compared to $95 \%$ in another [60]) suggesting that there would have been higher susceptibility to an allochthonous introduction of that strain. Although secular changes and reassortments unrelated to flood are known to occur following vaccine introduction $[61,62]$ and cannot be ruled out in this case, the fact that the emergence of G2P[4] rotavirus at this location occurred outside of the normal peak season and in conjunction with a similar appearance of the more unusual G3P[6] reassortant suggest that influences outside of the normal dynamics were at play. The appearance of genotypes with a recognized lower, but still significant vaccine efficacy suggests that rotavirus disease would likely have been significantly greater in the absence of immunization. This outbreak may also explain why overall rates of rotavirus transmission were unusually high at the MAL-ED Peru site in spite of high levels of vaccine uptake and compliance [63]. Modeling the risk ratios for specific genotypes in the same way as the main pathogen species in most cases yielded effect estimates that were so large as to be ungeneralizable outside of this very specific context.

Waterborne transmission occurs as a secondary route of transmission for all the other enteric viruses and both adenovirus and norovirus have been implicated in the scientific literature in outbreaks following extreme water-related weather events [64]. The most striking effect in absolute terms identified in this analysis was the sharp, off-season spike in sapovirus transmission that occurred around midway through the overall flood period. Historically, sapovirus has been underexplored relative to other enteric pathogens, so there is correspondingly little precedent for these findings in the scientific literature [65], and this study contributes to a growing body of evidence of the need for more population-based research into the epidemiology of this virus. The decreased risk of adenovirus in the early and astrovirus in the late flood periods are notable insofar as both occurred during the primary local annual peak in their transmission, suggesting that floodwaters may wash them from the environment, disrupting their seasonal trends [6].

This study was subject to several limitations. Given the restricted age range of subjects enrolled in MAL-ED, the study only identified infections in infants, while those occurring in later childhood, adolescence, or adulthood went undetected. Transmission patterns in response to flooding events may differ in older age groups. Furthermore, it was not possible to test specific hypotheses about the particular transmission pathways, since these may be pathogen-specific and require more resource intensive methods. Future research in this area may employ microbial source tracking to validate hypotheses about the relative contribution of humans compared to animals as pathogen reservoirs and clarify transmission routes [66].

These findings have several implications for policy-makers wishing to undertake preemptive strategies to reduce the risk of enteric disease outbreaks due to flooding. Firstly, while high vaccine coverage is necessary to sustain decreases in background rotavirus transmission levels, it may not prevent the local introduction of non-vaccine virus strains due to exogenous events such as flooding. More sustainable protection may be afforded by providing water sources that rely on groundwater reserves that are more resilient against viral contamination than surface sources [58]. Communities where household ownership of livestock is common may be at particular risk, suggesting that, community-level sustainable animal manure management interventions may prevent environmental contamination from livestock waste [67]. Lastly, in the context of three recent trials of water, sanitation, and hygiene (WASH) interventions that found at best only qualified impacts on diarrheal disease outcomes, this study adds further evidence to calls for a more radical, transformative WASH agenda [68]. Traditional low-cost, household-level improvements to water sources and sanitation facilities of the kind provided in such trials and by which progress towards WASH targets are measured, may simply be inadequate in the face of climate events that may suddenly and unexpectedly expose entire communities to large amounts of untreated sewage. Investments in more ambitious, municipal-level water, wastewater, and drainage infrastructure of the kind that have 
historically engendered society-wide child health improvements when implemented in high income countries may be the only sure route to climate resilience, if properly adapted to local contexts [68].

\section{Conclusions}

Causal inference approaches, such as interrupted time series, can be applied to population health surveillance data to shed light on the mechanisms behind disease transmission and quantify the effects of natural disasters. Using these methods, this analysis found that floods related to the La Niña phenomenon were associated with statistically and clinically significant increases in the risk of infection of two enteric viruses (rotavirus and sapovirus) and three enteric bacteria (Campylobacter spp., ST-ETEC, and Shigella spp.) after controlling for potential sources of bias and confounding. Policy-makers should target interventions towards these pathogens—including vaccines as they become available —in settings where vulnerability to flooding is high as part of disaster preparedness strategies. More generally, investments in radical, transformative, community-wide, and locally-tailored water and sanitation interventions are needed to ensure the resilience of vulnerable populations against the health impacts of extreme rainfall events.

Supplementary Materials: The following are available online at http://www.mdpi.com/1660-4601/17/2/487/s1, Figure S1: Needle plots of the daily distribution of pathogen-positive stool samples recorded at the MAL-ED Peru site by species.

Author Contributions: Conceptualization, J.C. and M.P.O.; methodology, J.C.; software, J.C.; validation, J.C., M.K. and M.P.O.; formal analysis, J.C.; investigation, M.P.O., P.P.Y., G.K., T.A., P.B., E.M., Z.B., P.S.S., A.L. and M.K.; resources, M.P.O., P.P.Y., G.K., T.A., P.B., E.M., Z.B., P.S.S., A.L. and M.K.; data curation, J.C.; writing-original draft preparation, J.C. and M.K.; writing—review and editing, J.C.; visualization, J.C.; supervision, M.K.; project administration, B.Z.; funding acquisition, B.Z., M.K., J.C. All authors have read and agreed to the published version of the manuscript.

Funding: The Etiology, Risk Factors, and Interactions of Enteric Infections and Malnutrition and the Consequences for Child Health and Development Project (MAL-ED) is carried out as a collaborative project supported by the Bill \& Melinda Gates Foundation (47075). The project obtained additional support from the BMGF under OPP1066146 and OPP1152146 (to MNK) and the Foundation for the National Institutes of Health, and the National Institutes of Health, Fogarty International Center. Additional support for MAL-ED was obtained from the Sherrilyn and Ken Fisher Center for Environmental Infectious Diseases of the Johns Hopkins School of Medicine (10KOS2015). The research presented in this Article was supported financially by NASA's Group on Earth Observations Work Program (16-GEO16-0047). The funders played no role in the design and implementation of the study or the analysis and interpretation of the results.

Acknowledgments: We thank the participants, their families, and the study communities for their dedicated time and effort to better the understanding the transmission and more enduring impact of enteric infections in early childhood on the health of individuals and populations. We also thank Elizabeth Stuart (Johns Hopkins Bloomberg School of Public Health) for consultation regarding the statistical analysis.

Conflicts of Interest: The authors declare no conflict of interest.

Ethical standards: Ethical approval for MAL-ED was given by the Johns Hopkins Institutional Review Board as well as from the respective partner institutions at each site. Written consent was obtained from all participants.

\section{References and Note}

1. Intergovernmental Panel on Climate Change (IPCC). Climate Change 2014: Impacts, Adaptation, and Vulnerability. 2014. Available online: http://www.ipcc.ch/report/ar5/wg2/ (accessed on 11 January 2020).

2. Watts, N.; Amann, M.; Arnell, N.; Ayeb-Karlsson, S.; Belesova, K.; Boykoff, M.; Byass, P.; Cai, W.; Campbell-Lendrum, D.; Capstick, S.; et al. The 2019 report of The Lancet Countdown on health and climate change: Ensuring that the health of a child born today is not defined by a changing climate. Lancet 2019, 394, 1836-1878. [CrossRef]

3. Intergovernmental Panel on Climate Change (IPCC) Working Group. Climate Change 2013: The Physical Science Basis; Intergovernmental Panel on Climate Change (IPCC) Working Group: Stockholm, Sweden, 2013.

4. Franchini, M.; Mannucci, P.M. Impact on human health of climate changes. Eur. J. Intern. Med. 2015, 26, 1-5. [CrossRef] [PubMed] 
5. Pop-Jordanova, N.; Grigorova, E. Influence of Climate Changes on Health (Review). Prilozi 2015, 36, 119-125. [CrossRef] [PubMed]

6. Levy, K.; Woster, A.P.; Goldstein, R.S.; Carlton, E.J. Untangling the Impacts of Climate Change on Waterborne Diseases: A Systematic Review of Relationships between Diarrheal Diseases and Temperature, Rainfall, Flooding, and Drought. Environ. Sci. Technol. 2016, 50, 4905-4922. [CrossRef] [PubMed]

7. Wade, T.J.; Lin, C.J.; Jagai, J.S.; Hilborn, E.D. Flooding and Emergency Room Visits for Gastrointestinal Illness in Massachusetts: A Case-Crossover Study. PLoS ONE 2014, 9, e110474. [CrossRef] [PubMed]

8. Intergovernmental Panel on Climate Change (IPCC). Climate Change 2007: Impacts, Adaptation, and Vulnerability; Intergovernmental Panel on Climate Change (IPCC): Cambridge, UK; New York, NY, USA, 2007.

9. Alderman, K.; Turner, L.R.; Tong, S. Floods and human health: A systematic review. Environ. Int. 2012, 47, 37-47. [CrossRef]

10. Satyamurty, P.; Da Costa, C.P.W.; Manzi, A.O.; Candido, L.A. A quick look at the 2012 record flood in the Amazon Basin. Geophys. Res. Lett. 2013, 40, 1396-1401. [CrossRef]

11. Espinoza, J.C.; Ronchail, J.; Frappart, F.; Lavado, W.; Santini, W.; Guyot, J.L.; Lavado-Casimiro, W. The Major Floods in the Amazonas River and Tributaries (Western Amazon Basin) during the 1970-2012 Period: A Focus on the 2012 Flood. J. Hydrometeorol. 2013, 14, 1000-1008. [CrossRef]

12. Barichivich, J.; Gloor, E.; Peylin, P.; Brienen, R.J.W.; Schöngart, J.; Espinoza, J.C.; Pattnayak, K.C. Recent intensification of Amazon flooding extremes driven by strengthened Walker circulation. Sci. Adv. 2018, 4, eaat8785. [CrossRef]

13. Levy, K.; Hubbard, A.E.; Eisenberg, J.N.S. Seasonality of rotavirus disease in the tropics: A systematic review and meta-analysis. Int. J. Epidemiol. 2009, 38, 1487-1496. [CrossRef]

14. Hellberg, R.S.; Chu, E. Effects of climate change on the persistence and dispersal of foodborne bacterial pathogens in the outdoor environment: A review. Crit. Rev. Microbiol. 2016, 42, 548-572. [CrossRef] [PubMed]

15. Lal, A.; Hales, S.; French, N.; Baker, M.G. Seasonality in Human Zoonotic Enteric Diseases: A Systematic Review. PLoS ONE 2012, 7, e31883. [CrossRef] [PubMed]

16. Chowdhury, F.R.; Ibrahim, Q.S.U.; Bari, S.; Alam, M.M.J.; Dunachie, S.J.; Rodriguez-Morales, A.J.; Patwary, I. The association between temperature, rainfall and humidity with common climate-sensitive infectious diseases in Bangladesh. PLoS ONE 2018, 13, e0199579. [CrossRef] [PubMed]

17. Harris, A.M.; Chowdhury, F.; Begum, Y.A.; Khan, A.I.; Faruque, A.S.G.; Svennerholm, A.-M.; Harris, J.B.; Ryan, E.T.; Cravioto, A.; Calderwood, S.B.; et al. Shifting prevalence of major diarrheal pathogens in patients seeking hospital care during floods in 1998, 2004, and 2007 in Dhaka, Bangladesh. Am. J. Trop. Med. Hyg. 2008, 79, 708-714. [CrossRef]

18. Sterk, A.; Schijven, J.; De Nijs, T.; Husman, A.M.D.R. Direct and Indirect Effects of Climate Change on the Risk of Infection by Water-Transmitted Pathogens. Environ. Sci. Technol. 2013, 47, 12648-12660. [CrossRef]

19. Rieckmann, A.; Tamason, C.C.; Gurley, E.S.; Rod, N.H.; Jensen, P.K.M. Exploring Droughts and Floods and Their Association with Cholera Outbreaks in Sub-Saharan Africa: A Register-Based Ecological Study from 1990 to 2010. Am. J. Trop. Med. Hyg. 2018, 98, 1269-1274. [CrossRef]

20. Saulnier, D.D.; Ribacke, K.B.; Von Schreeb, J. No Calm After the Storm: A Systematic Review of Human Health Following Flood and Storm Disasters. Prehospital Disaster Med. 2017, 32, 568-579. [CrossRef]

21. Schwartz, B.S.; Harris, J.B.; Khan, A.I.; Larocque, R.C.; Sack, D.A.; Malek, M.A.; Faruque, A.S.G.; Qadri, F.; Calderwood, S.B.; Luby, S.P.; et al. Diarrheal epidemics in Dhaka, Bangladesh, during three consecutive floods: 1988, 1998, and 2004. Am. J. Trop. Med. Hyg. 2006, 74, 1067-1073. [CrossRef]

22. Liu, X.; Liu, Z.; Zhang, Y.; Jiang, B. Quantitative analysis of burden of bacillary dysentery associated with floods in Hunan, China. Sci. Total. Environ. 2016, 547, 190-196. [CrossRef]

23. Zhang, N.; Song, D.; Zhang, J.; Liao, W.; Miao, K.; Zhong, S.; Lin, S.; Hajat, S.; Yang, L.; Huang, C. The impact of the 2016 flood event in Anhui Province, China on infectious diarrhea disease: An interrupted time-series study. Environ. Int. 2019, 127, 801-809. [CrossRef]

24. Ding, G.; Zhang, Y.; Gao, L.; Ma, W.; Li, X.; Liu, J.; Liu, Q.; Jiang, B. Quantitative Analysis of Burden of Infectious Diarrhea Associated with Floods in Northwest of Anhui Province, China: A Mixed Method Evaluation. PLoS ONE 2013, 8, e65112. [CrossRef]

25. Kotloff, K.L. The Burden and Etiology of Diarrheal Illness in Developing Countries. Pediatr. Clin. N. Am. 2017, 64, 799-814. [CrossRef] 
26. A Platts-Mills, J.; Liu, J.; Rogawski, E.T.; Kabir, F.; Lertsethtakarn, P.; Siguas, M.; Khan, S.S.; Praharaj, I.; Murei, A.; Nshama, R.; et al. Use of quantitative molecular diagnostic methods to assess the aetiology, burden, and clinical characteristics of diarrhoea in children in low-resource settings: A reanalysis of the MAL-ED cohort study. Lancet Glob. Heal. 2018, 6, e1309-e1318. [CrossRef]

27. Lima, A.A.M.; Oliveira, D.B.; Quetz, J.S.; Havt, A.; Prata, M.M.G.; Lima, I.F.N.; Soares, A.M.; Filho, J.Q.; Lima, N.L.; Medeiros, P.H.Q.S.; et al. Etiology and severity of diarrheal diseases in infants at the semiarid region of Brazil: A case-control study. PLoS Negl. Trop. Dis. 2019, 13, e0007154. [CrossRef]

28. MAL-ED Network Investigators, The MAL-ED Network Investigators, MAL-ED Network Investigators. The MAL-ED study: A multinational and multidisciplinary approach to understand the relationship between enteric pathogens, malnutrition, gut physiology, physical growth, cognitive development, and immune responses in infants and children up to 2 years of. Clin. Infect. Dis. 2014, 59, S193-S206. [CrossRef]

29. Yori, P.P.; Lee, G.; Olórtegui, M.P.; Chávez, C.B.; Flores, J.T.; Vasquez, A.O.; Burga, R.; Pinedo, S.R.; Asayag, C.R.; Black, R.E.; et al. Santa Clara de Nanay: The MAL-ED Cohort in Peru. Clin. Infect. Dis. 2014, 59, S310-S316. [CrossRef]

30. Andina. Senamhi Declara Alerta Roja Hidrológica Por Incremento de Caudal de Ríos Amazónicos. Agencia peru. Not. 2012. Available online: https://web.archive.org/web/20120406171822/http://www.andina.com.pe/ Espanol/noticia-senamhi-declara-alerta-roja-hidrologica-incremento-rios-amazonicos-403809 (accessed on 4 November 2019).

31. Rosa Cárdenas. Decretan Estado de Emergencia en Parte de Loreto Por Inundaciones. La República. 2012. Available online: https://arepublica.pe/archivo/620955-decretan-estado-de-emergencia-en-parte-de-loretopor-inundaciones (accessed on 4 November 2019).

32. National Oceanic and Atmospheric Administration. NNDC Climate Data Online. NOAA Satallite Inf. Serv. 2016. Available online: https://www7.ncdc.noaa.gov/CDO/cdoselect.cmd?datasetabbv=GSOD\& countryabbv=\&georegionabbv (accessed on 1 January 2017).

33. Sede de Loreto. Nivel del Rio Nanay 1969-2015. Iquitos, (Restricted Circulation). 2015.

34. OFDA/CRED. International Disaster Database; Université Catholique de Louvain: Brussels, Belgium, 2013; Available online: http://www.emdat.be (accessed on 5 February 2013).

35. Liu, J.; Gratz, J.; Amour, C.; Nshama, R.; Walongo, T.; Maro, A.; Mduma, E.; Boisen, N.; Nataro, J.; Doris, M.; et al. Optimization of Quantitative PCR Methods for Enteropathogen Detection. Chan KH, editor. PLoS ONE 2016, 11, e0158199.

36. Houpt, E.; Gratz, J.; Kosek, M.; Zaidi, A.K.M.; Qureshi, S.; Kang, G.; Babji, S.; Mason, C.; Bodhidatta, L.; Samie, A.; et al. Microbiologic methods utilized in the MAL-ED cohort study. Clin. Infect. Dis. 2014, 59, S225-S232. [CrossRef]

37. Linden, A.; Adams, J.L. Applying a propensity score-based weighting model to interrupted time series data: Improving causal inference in programme evaluation. J. Eval. Clin. Pract. 2011, 17, 1231-1238. [CrossRef]

38. Biglan, A.; Ary, D.; Wagenaar, A.C. The value of interrupted time-series experiments for community intervention research. Prev. Sci. 2000, 1, 31-49. [CrossRef]

39. Colston, J.M.; Ahmed, A.M.S.; Soofi, S.B.; Svensen, E.; Haque, R.; Shrestha, J.; Nshama, R.; Bhutta, Z.; Lima, I.F.N.; Samie, A.; et al. Seasonality and within-subject clustering of rotavirus infections in an eight-site birth cohort study. Epidemiol. Infect. 2018, 146, 688-697. [CrossRef] [PubMed]

40. Colston, J.M.; Zaitchik, B.; Kang, G.; Yori, P.P.; Ahmed, T.; Lima, A.; Turab, A.; Mduma, E.; Shrestha, P.S.; Bessong, P.; et al. Use of earth observation-derived hydrometeorological variables to model and predict rotavirus infection (MAL-ED): A multisite cohort study. Lancet Planet. Heal. 2019, 3, e248-e258. [CrossRef]

41. Zou, G. A modified poisson regression approach to prospective studies with binary data. Am. J. Epidemiol. 2004, 159, 702-706. [CrossRef] [PubMed]

42. StataCorp. Stata Statistical Software: Release 15; StataCorp: College Station, TX, USA, 2017.

43. Bennett, A.; Epstein, L.D.; Gilman, R.H.; Cama, V.; Bern, C.; Cabrera, L.; Lescano, A.G.; Patz, J.; Carcamo, C.; Sterling, C.R.; et al. Effects of the 1997-1998 El Niño Episode on Community Rates of Diarrhea. Am. J. Public Heal. 2012, 102, e63-e69. [CrossRef]

44. Demissie, S. The Impact of El Niño on Diarrheal Disease Incidence: A Systematic Review. Sci. J. Public Heal. 2017, 5, 446. [CrossRef]

45. Fisman, D.N.; Tuite, A.R.; Brown, K.A. Impact of El Niño Southern Oscillation on infectious disease hospitalization risk in the United States. Proc. Natl. Acad. Sci. USA 2016, 113, 14589-14594. [CrossRef] 
46. Perry, S.J.; McGregor, S.; Gupta, A.S.; England, M.H. Future Changes to El Niño-Southern Oscillation Temperature and Precipitation Teleconnections. Geophys. Res. Lett. 2017, 44, 10608-10616. [CrossRef]

47. Latif, M.; Keenlyside, N.S. El Niño/Southern Oscillation response to global warming. Proc. Natl. Acad. Sci. USA 2009, 106, 20578-20583. [CrossRef]

48. Liu, J.; A Platts-Mills, J.; Juma, J.; Kabir, F.; Nkeze, J.; Okoi, C.; Operario, D.J.; Uddin, J.; Ahmed, S.; Alonso, P.L.; et al. Use of quantitative molecular diagnostic methods to identify causes of diarrhoea in children: A reanalysis of the GEMS case-control study. Lancet 2016, 388, 1291-1301. [CrossRef]

49. Qadri, F.; Khan, A.I.; Faruque, A.S.G.; Begum, Y.A.; Chowdhury, F.; Nair, G.B.; Salam, M.A.; Sack, D.A.; Svennerholm, A.M. Enterotoxigenic Escherichia coli and Vibrio cholerae diarrhea, Bangladesh, 2004. Emerg. Infect. Dis. 2005, 11, 1104. [CrossRef]

50. Gonzales-Siles, L.; Sjöling, Å. The different ecological niches of enterotoxigenic E scherichia coli. Environ. Microbiol. 2016, 18, 741-751. [CrossRef] [PubMed]

51. Hu, T.-L.; Kuo, P.-C. Isolation of Campylobacter sp in surface waters of Taiwan. J. Microbiol. Immunol. Infect. 2011, 44, 15-20. [CrossRef] [PubMed]

52. Macdonald, E.; White, R.; Mexía, R.; Bruun, T.; Kapperud, G.; Lange, H.; Nygard, K.; Vold, L. Risk Factors for Sporadic Domestically Acquired Campylobacter Infections in Norway 2010-2011: A National Prospective Case-Control Study. PLoS ONE 2015, 10, e0139636. [CrossRef]

53. Soneja, S.; Jiang, C.; Upperman, C.R.; Murtugudde, R.; Mitchell, C.S.; Blythe, D.; Sapkota, A.R.; Sapkota, A. Extreme precipitation events and increased risk of campylobacteriosis in Maryland, USA. Environ. Res. 2016, 149, 216-221. [CrossRef] [PubMed]

54. Kraay, A.N.M.; Brouwer, A.F.; Lin, N.; Collender, P.A.; Remais, J.V.; Eisenberg, J.N.S. Modeling environmentally mediated rotavirus transmission: The role of temperature and hydrologic factors. Proc. Natl. Acad. Sci. USA 2018, 115, E2782-E2790. [CrossRef] [PubMed]

55. Jones, F.K.; Ko, A.I.; Becha, C.; Joshua, C.; Musto, J.; Thomas, S.; Ronsse, A.; Kirkwood, C.D.; Sio, A.; Aumua, A.; et al. Increased Rotavirus Prevalence in Diarrheal Outbreak Precipitated by Localized Flooding, Solomon Islands, 2014. Emerg. Infect. Dis. 2016, 22, 875-879. [CrossRef]

56. Hasan, M.A.; Mouw, C.; Jutla, A.; Akanda, A.S. Quantification of Rotavirus Diarrheal Risk Due to Hydroclimatic Extremes Over South Asia: Prospects of Satellite-Based Observations in Detecting Outbreaks. GeoHealth 2018, 2, 70-86. [CrossRef]

57. Sarkar, R.; Kang, G.; Naumova, E.N. Rotavirus Seasonality and Age Effects in a Birth Cohort Study of Southern India. PLoS ONE 2013, 8, e71616. [CrossRef]

58. Martinez, P.P.; Mahmud, A.S.; Yunus, M.; Faruque, A.S.G.; Ahmed, T.; Pascual, M.; O Buckee, C. Tube Well Use as Protection against Rotavirus Infection during the Monsoons in an Urban Setting. J. Infect. Dis. 2019, 221, 238-242. [CrossRef]

59. Ruiz-Palacios, G.M.; Perez-Schael, I.; Velázquez, F.R.; Abate, H.; Breuer, T.; Clemens, S.C.; Cheuvart, B.; Espinoza, F.; Gillard, P.; Innis, B.L.; et al. Safety and Efficacy of an Attenuated Vaccine against Severe Rotavirus Gastroenteritis. N. Engl. J. Med. 2006, 354, 11-22. [CrossRef]

60. Matthijnssens, J.; Zeller, M.; Heylen, E.; De Coster, S.; Vercauteren, J.; Braeckman, T.; Van Herck, K.; Meyer, N.; Pircon, J.-Y.; Soriano-Gabarro, M.; et al. Higher proportion of G2P[4] rotaviruses in vaccinated hospitalized cases compared with unvaccinated hospitalized cases, despite high vaccine effectiveness against heterotypic G2P[4] rotaviruses. Clin. Microbiol. Infect. 2014, 20, O702-O710. [CrossRef] [PubMed]

61. Vizzi, E.; Piñeros, O.A.; Oropeza, M.D.; Naranjo, L.; Suárez, J.A.; Fernández, R.; Zambrano, J.L.; Celis, A.; Liprandi, F. Human rotavirus strains circulating in Venezuela after vaccine introduction: Predominance of G2P[4] and reemergence of G1P[8]. Virol. J. 2017, 14, 58. [CrossRef] [PubMed]

62. Thanh, H.D.; Tran, V.T.; Lim, I.; Kim, W. Emergence of Human G2P[4] Rotaviruses in the Post-vaccination Era in South Korea: Footprints of Multiple Interspecies Re-assortment Events. Sci. Rep. 2018, 8, 6011. [CrossRef] [PubMed]

63. Mohan, V.R.; Karthikeyan, R.; Babji, S.; McGrath, M.; Shrestha, S.; Shrestha, J.; Mdumah, E.; Amour, C.; Samie, A.; Nyathi, E.; et al. Rotavirus Infection and Disease in a Multisite Birth Cohort: Results From the MAL-ED Study. J. Infect. Dis. 2017, 216, 305-316. [CrossRef]

64. Cann, K.F.; Thomas, D.R.; Salmon, R.L.; Wyn-Jones, A.P.; Kay, D. Extreme water-related weather events and waterborne disease. Epidemiol. Infect. 2013, 141, 671-686. [CrossRef] 
65. Hall, A.J.; Lopman, B.A.; Vinjé, J. Sapovirus. In Foodborne Infections and Intoxications; Elsevier BV: Amsterdam, The Nederland, 2013; pp. 313-319.

66. Fu, L.L.; Li, J.R. Microbial Source Tracking: A Tool for Identifying Sources of Microbial Contamination in the Food Chain. Crit. Rev. Food Sci. Nutr. 2014, 54, 699-707. [CrossRef]

67. Malomo, G.A.; Madugu, A.S.; Bolu, S.A. Sustainable Animal Manure Management Strategies and Practices. Agric. Waste Residues 2018, 119, 121-137.

68. Cumming, O.; Arnold, B.F.; Ban, R.; Clasen, T.; Mills, J.E.; Freeman, M.C.; Gordon, B.; Guiteras, R.; Howard, G.; Hunter, P.R.; et al. The implications of three major new trials for the effect of water, sanitation and hygiene on childhood diarrhea and stunting: A consensus statement. BMC Med. 2019, 17, 173. [CrossRef]

(C) 2020 by the authors. Licensee MDPI, Basel, Switzerland. This article is an open access article distributed under the terms and conditions of the Creative Commons Attribution (CC BY) license (http://creativecommons.org/licenses/by/4.0/). 